American Journal of Applied Sciences 6 (3): 492-497, 2009

ISSN 1546-9239

(C) 2009 Science Publications

\title{
Identification and Quantification of Major Carotenoids in Some Vegetables
}

\author{
Jafar Muhammad EL-Qudah \\ Department of Nutrition and Food Processing, Faculty of Agricultural Technology, \\ Al-Balqa Applied University, 19117 Al-Salt, Jordan
}

\begin{abstract}
An HPLC study of 6 raw vegetables (Okra, green beans, eggplant zucchini, carrot and tomato) most frequently consumed worldwide was carried out to determine their carotenoid composition. The samples were purchased from supermarket in the city of Boston, USA. Neoxanthin, violaxanthin and lutein were contained in all samples except tomato for neoxanthin, carrot and tomato for violaxanthin and carrot for lutein. $\beta$-carotene was contained in all samples while $\alpha$-carotene was contained only in carrot. Lycopene was contained in okra, green beans and tomato. Carrot had $\alpha-$ carotene and $\beta$-carotene as principal carotenoids and lutein as minor component. Relatively high ratios (9-cis to all-trans $\beta$-carotene) of above $0.2 \mathrm{~g} / \mathrm{g}$ were noted in green beans, eggplant and okra.
\end{abstract}

Key words: carotenoids, vegetables, HPLC, $\beta$-carotene, lutein, Jordan

\section{INTRODUCTION}

Carotenoids are fat soluble compounds that are associated with the lipidic fractions. From a chemical point of view, carotenoids are polyisoprenoid compounds and can be divided into two main groups: (a) carotenes or hydrocarbon carotenoids only composed of carbon and hydrogen atoms and (b) xanthophylls that are oxygenated hydrocarbon derivatives that contain at least one oxygen function such as hydroxyl, keto, epoxy, methoxy or carboxylic acid groups. Their structural characteristic is a conjugated double bond system, which influences their chemical, biochemical and physical properties.

Carotenoids are a class of natural pigments occurs widely in nature. They are synthesized by plants and many microorganisms, so animals have to obtain them from food. Up to now, more than 600 carotenoids have so far been isolated from natural sources. However, only about 40 are present in a typical human diet. Of these 40 about 20 carotenoids have been identified in human blood and tissues ${ }^{[1]}$.

Fruits and vegetables containing vitamin $C$, vitamin $\mathrm{E}$ (tocopherols) and carotenoids ( $\alpha$-carotene, $\beta$ carotene, $\beta$-cryptoxanthin, lutein, zeaxanthin and lycopene) have been suggested as a natural source of antioxidants. Antioxidant functions are associated with decreased DNA damage, diminished lipid peroxidation, maintained immune function and inhibited malignant transformation or proliferation in vitro that are thought to prevent the development of some diseases ${ }^{[2,3]}$. Also, $\alpha$-carotene, $\beta$-carotene and $\beta$-cryptoxanthin are considered as provitamin A carotenoids ${ }^{[4]}$. More over, it is generally accepted that the significance of vegetable consumption can play an important role in maintaining health and reducing the risk of illness ${ }^{[5]}$. In particular, increased vegetable consumption helps reduce the risk of cancer ${ }^{[6]}$. That is why vegetables as well as fruits are widely recommended as healthy food ${ }^{[7]}$. Vegetables are also a valuable part of the diet owing to their nutritive values ${ }^{[8]}$. They are low in energy containing limited amounts of carbohydrates and fats and high in dietary fiber, minerals and vitamins.

Carotenoids, provitamins A or not, have been credited with other beneficial effects to human health: enhancement of the immune response and reduction of the risk of degenerative diseases such as cancer, cardiovascular diseases, cataract and muscular degeneration ${ }^{[9-13]}$. The carotenoids' action against diseases has been attributed to antioxidant activity, specifically to their ability to quench singlet oxygen and interact with free radicals ${ }^{[14-16]}$. However, other mechanisms have been reported such as modulation of carcinogen metabolism, regulation of cell growth, inhibition of cell proliferation, enhancement of cell differentiation, stimulation of cell-to-cell gap junctional communication, retinoid-dependent signaling and filtering of blue light ${ }^{[12,13,17-19]}$.

The vegetables analyzed in this paper are consumed worldwide. These vegetables also are grown, harvested and consumed widely by the Middle East population including Jordan. The carotenoid contents of Okra, green beans, zucchini, eggplant, tomato and carrot have been determined in several countries but the results are somewhat diverging. More data obtained by reliable methods are needed even for these vegetables 
in order to differentiate natural compositional variation from analytical variability.

\section{MATERIALS AND METHODS}

The experimental work was carried out at Carotenoids and Health Laboratory, Jean Mayer USDA Human Nutrition Research Center on Aging (HNRCA), Tufts University, Boston, USA.

Reagent, chemicals and source of sample: All-trans$\beta$-carotene, 9 -cis- $\beta$-carotene, $\alpha$-carotene, lutein, zeaxanthin, lycopene, Methyl-Tert-Butyl Ether (MTBE) and ammonium acetate (analytical grade) were purchased from Sigma Company (St Louis, MO, USA). Milli Q water was obtained from Water Purification Systems and used for all procedures using water. Tetra Hydro Furan (THF) and methanol were purchased from JT Baker Chemical (Philipsburg,NJ). Vegetables were purchased at a vegetable market from Boston, MA, USA.

Chromatography and HPLC analysis: Carotenoids were quantified using a high-performance liquid chromatographic (HPLC) system equipped with C30 column ( $3 \mu \mathrm{m}, 150 \times 4.6 \mathrm{~mm}$, YMC, Wilmington, $\mathrm{NC}$, USA).Carotenoids were monitored at $455 \mathrm{~nm}$, with a Waters 2996 photodiode array detector (Milford, MA, USA). The HPLC mobile phases were methanol: Methyl-Tert-Butyl Ether (MTBE): water (85:12:3 by volume, with $1.5 \%$ ammonium acetate in water) for solvent $A$ and methanol: MTBE: water (8:90:2 by volume, with $1.0 \%$ ammonium acetate in water) for solvent B. The gradient procedure, was as follows: (1) start at $100 \%$ solvent $\mathrm{A},(2)$ a 21 min linear gradient to $45 \%$ solvent $\mathrm{A}$ and $55 \%$ solvent $\mathrm{B}$, (3) 1 min hold at $45 \%$ solvent $\mathrm{A}$ and $55 \%$ solvent $\mathrm{B}$, (4) an 11 min linear gradient to $5 \%$ solvent $\mathrm{A}$ and $95 \%$ solvent $\mathrm{B},(5)$ a 4 min hold at 5\% solvent $A$ and $95 \%$ solvent $B,(6)$ a 2 min linear gradient back to $100 \%$ solvent $A,(7)$ a 28 min hold at $100 \%$ solvent $\mathrm{A}$. The flow rate was $0.4 \mathrm{ml}$ $\min ^{-1}$ and the injection volume was $20 \mu \mathrm{l}$. Carotenoids were quantified by determining peak areas under the curve in the high-performance liquid chromatograms calibrated against known amounts of standards. Each peak was confirmed by the retention time and characteristic spectra of the standards.

Sample preparation: The extraction of the vegetable, using a modified procedure from Riso and Porrini ${ }^{[20]}$, was performed by incubating $500 \mathrm{mg}$ of the pureed vegetable together with $10 \mathrm{~mL}$ methanol for $1 \mathrm{~h}$ in a shaking incubator at $120 \mathrm{rpm}$. Afterwards, the mixture was homogenized for $30 \mathrm{sec}$ in an ice bath and the probe washed with methanol. The mixture was centrifuged at $3000 \mathrm{rpm}$ for $5 \mathrm{~min}$. The methanol layer was transferred into a $50 \mathrm{~mL}$ volumetric flask and the extraction repeated four times with $10 \mathrm{~mL}$ of Tetra Hydro Furan (THF), followed by vortexing and centrifugation. The THF layers were combined with the methanol layer and the volume brought up to $50 \mathrm{~mL}$. One $\mathrm{mL}$ of the extract was taken, dried under nitrogen and re-suspended in $1 \mathrm{~mL}$ of ethanol. Triplet samples of each vegetable were extracted.

All the necessary precautions were taken to avoid losses of carotenoids and other errors during analysis, e.g., working under red lights, finishing the analysis within the shortest possible time, exclusion of oxygen, avoiding high temperature and contact with acids, using high purity solvents, exhaustive extraction .

\section{RESULTS AND DISCUSSION}

Common English, Arabic and Scientific names of vegetables included in this study are given in Table 1. Fig. 1a, b, c, d, e and f shows chromatographic profiles of vegetables (okra, green beans, eggplant, zucchini, carrot and tomato) respectively. The principal carotenoids were lutein, neoxanthin, violaxanthin and $\beta$-carotene. Okra also had 9-cis- $\beta$-carotene and 13-cis$\beta$-carotene as major carotenoids (Fig. 1a). Cis-lutein and zeaxanthin were detected in zucchini (Fig. 1d). Carrots had $\alpha$-carotene and $\beta$-carotene as the main carotenoids and neoxanthin as minor component (Fig. 1e). Lycopene predominated in tomato (Fig. 1f) and was detected also in okra and green beans (Fig. 1a and $b)$ respectively.

The means of carotenoids contents of raw vegetables are given in Table 2, along with those nutrient contents from the USDA database ${ }^{[21]}$ and other published databases $^{[22-25]}$ to enable comparisons of values obtained in the present study. In general, all the vegetables analyzed appeared to be considerable sources of carotenoids, with the exception of eggplant which had lower carotenoids content. All raw

Table 1: Common English, Arabic and scientific names of vegetables included in this study

\begin{tabular}{lll}
\hline Common English name & Arabic name & Scientific name \\
\hline Okra & Bamia & Abelmoschus esculentus \\
Green beans & Fasolia & Phaseolus coccineus \\
Eggplant & Bazinjan & Solanum melongena \\
Zucchini & Kussa & Cucurbita pepo \\
Carrot & Jazar & Daucus carota L. \\
Tomato & Bandora & Lycopersicum esculentus \\
\hline
\end{tabular}



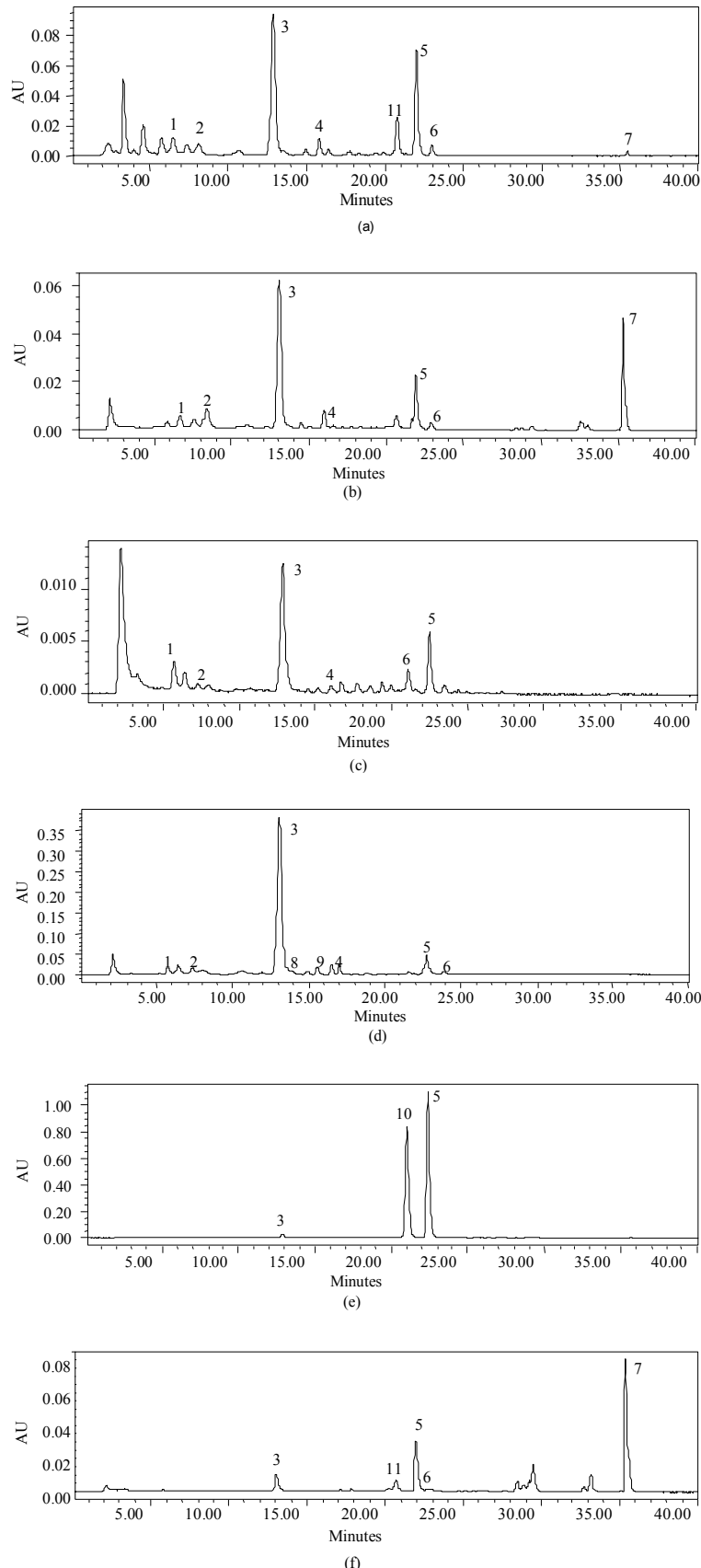

Fig. 1:Typical HPLC chromatograms of the carotenoids of (a) Okra, (b) Green beans, (c) Eggplant, (d) Zucchini, (e) Carrot and (f) Tomato. Peak identification: (1) neoxanthin, (2) violaxanthin, (3) lutein, (4) chlorophylls, (5) $\beta$-carotene, (6) 9cis- $\beta$-carotene, (7) lycopene, (8) zeaxanthin, (9) cis-lutein, (10) $\alpha$-carotene, (11) 13 -cis- $\beta$ carotene vegetables in this study contained $\beta$-carotene and lutein with the exception of carrot which contained only $\beta$ carotene. Good sources of xanthophylls were zucchini, okra and green beans, in agreement with previously published data ${ }^{[22,23,26]}$. Although these carotenoids are not provitamins A, but the antioxidant property is linked with the conjugated double bond system, the maximum protection being giving by carotenoids having more than nine double bonds ${ }^{[27]}$. The $\beta$-carotene content of okra, green beans, carrot and tomato were much lower than that from both the USDA and other databases. These differences may be due to maturity of the vegetables, geographic or varietal differences.

All raw vegetables in the present study did not contain detectable levels of zeaxanthin, except zucchini which contained $0.41 \mu \mathrm{g} \mathrm{g}^{-1}$. Only carrot had $\alpha-$ carotene $47.1 \mu \mathrm{g} \mathrm{g}^{-1}$ edible portion and contained also the highest $\beta$-carotene $\left(47.5 \mu \mathrm{g} \mathrm{g}^{-1}\right)$. In contrast, 9-cis$\beta$-carotene was found in all vegetables, except carrot, while 13-cis- $\beta$-carotene was found in both okra and tomato. All the $\beta$-carotene containing vegetables presented high ratios of 9-cis to all-trans $\beta$-carotene, ranging from 0.52 in green beans, 0.5 in eggplant, 0.22 in okra, 0.12 in zucchini down to 0.05 in tomato. The lack of literature information on the content of 9-cis $\beta$ carotene in plants and 13-cis- $\beta$-carotene may be related to previous use of non-appropriate analytical conditions for identification of 9 -cis- $\beta$-carotene and 13 -cis $\beta$ carotene and other stereoisomers of carotenoids ${ }^{[23]}$. Experimental nutritional medical studies with natural carotenoids, isomers of carotenes and carotenoids originating from different plant sources, have been limited. The present study and related previously published studies on natural carotenoids in plants, show that, even within the scope of $\beta$-carotene itself, more attention should be paid to the stereoisomeric configuration. The possible metabolic conversion of 9cis $\beta$-carotene to 9-cis retinoic acid was recently reported and it is now considered as a potential medicine in certain types of tumours ${ }^{[23,28]}$.

The principal carotenoids found in foods are: $\beta$ carotene, $\alpha$-carotene, $\beta$-cryptoxanthin, lycopene,lutein and violaxanthin. With the exception of violaxanthin, these carotenoids are also the most commonly found in the human plasma and have been, together with zeaxanthin, the most studied in terms of health promoting effects.

The experimental data showed large variations in carotenoid content of the foods assayed in this study. Prior and $\mathrm{Cao}^{[29]}$ documented factors such as cultivars, maturity and other environmental factors such as 
Am. J. Applied Sci., 6 (3): 492-497, 2009

Table 2: Carotenoid contents, edible portion, of raw vegetables ${ }^{\text {a }}$

\begin{tabular}{|c|c|c|c|c|c|c|c|c|c|c|}
\hline \multirow[b]{2}{*}{ Vegetables } & \multicolumn{10}{|c|}{ Concentration $\left(\mu \mathrm{g} \mathrm{g}^{-1}\right)$} \\
\hline & Neox & Viol & Lutein & cis-lutein & $\alpha$-Carot & $\beta$-Carot & Zeax & 9-cis $\beta$-Carot & 13-cis $\beta$-Carot & Lycop \\
\hline \multicolumn{11}{|c|}{ 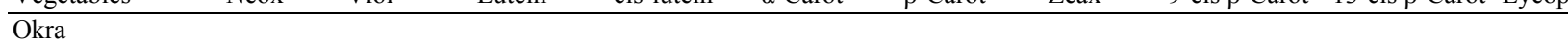 } \\
\hline This study ${ }^{b}$ & 2.08 & 1.58 & 8.98 & $-{ }^{c}$ & - & 1.93 & - & 0.43 & 2.12 & 0.19 \\
\hline $\mathrm{USDA}^{\mathrm{d}}$ & - & - & $5.16^{\mathrm{e}}$ & - & 0 & 2.25 & - & - & - & 0 \\
\hline Others ${ }^{\mathrm{f}}$ & - & - & - & _- & - & 0.69 & - & - & - & - \\
\hline \multicolumn{11}{|l|}{ Green beans } \\
\hline This study & 0.47 & 0.81 & 4.78 & - & - & 0.23 & - & 0.12 & - & 1.85 \\
\hline USDA & - & - & 6.4 & - & 0.69 & 3.79 & - & - & - & 0 \\
\hline Others $^{\mathrm{f}}$ & - & - & - & - & - & 2.39 & - & - & - & - \\
\hline \multicolumn{11}{|l|}{ Eggplant } \\
\hline This study & 0.23 & 0.11 & 0.71 & _ & _- & 0.18 & _ & 0.09 & _ & _ \\
\hline USDA & - & - & 0 & - & 0 & 0.16 & 0 & - & - & 0 \\
\hline Others $^{\mathrm{g}}$ & 2 & - & 9.6 & - & 2.3 & - & 1.3 & - & - & 27.4 \\
\hline \multicolumn{11}{|l|}{ Zucchini } \\
\hline This study & 1.46 & 1.21 & 23.4 & 0.23 & - & 1.46 & 0.41 & 0.17 & - & - \\
\hline USDA & - & - & 21.25 & - & 0 & 1.2 & - & - & - & 0 \\
\hline Others $^{\mathrm{g}}$ & 0.9 & 0.6 & 33.2 & - & 0.1 & 1.3 & - & - & - & 0.3 \\
\hline Others $^{\mathrm{h}}$ & - & 6.9 & 9.8 & - & - & 5.4 & - & - & - & - \\
\hline \multicolumn{11}{|l|}{ Carrot } \\
\hline This study & 1.33 & - & - & - & 47.1 & 47.5 & - & - & - & - \\
\hline USDA & - & - & 3.58 & - & 37.67 & 63.91 & _ & - & _- & 0 \\
\hline Others $^{g}$ & 0.5 & 0.1 & 7.8 & - & 425 & 1030 & 57.4 & 57.1 & - & - \\
\hline Others ${ }^{\mathrm{i}}$ & - & - & 5.1 & - & 35 & 61 & - & - & - & - \\
\hline \multicolumn{11}{|l|}{ Tomato } \\
\hline This study & - & - & 0.39 & _ & _ & 0.79 & _ & 0.04 & 0.32 & 2.11 \\
\hline USDA & - & - & 1.23 & - & 1.01 & 4.49 & - & - & - & 25.73 \\
\hline Others $^{\mathrm{g}}$ & 7.6 & 9 & 14.3 & - & - & 14.5 & - & - & - & 243.1 \\
\hline Others ${ }^{\mathrm{i}}$ & - & - & 1 & - & - & 3.2 & - & - & - & 35.4 \\
\hline
\end{tabular}

${ }^{a}$ Neox, neoxanthin, Viol, violaxanthin, $\alpha$-Carot, $\alpha$-carotene, $\beta$-Carot, $\beta$-carotene, Zeax, zeaxanthin, Lycop,lycopene

${ }^{b}$ Values represent mean of three measurements

${ }^{c}$ Not determined

${ }^{\mathrm{d}}$ USDA National Nutrient Databases for Standard Reference, Release 20(2007)

${ }^{\mathrm{e}}$ Value of lutein and zeaxanthin

${ }^{\mathrm{f}}$ Kandlakunte et al. (2008)

${ }^{\mathrm{g}}$ Ben-Amotz and Fishler (1997). $\left(\mu \mathrm{g} \mathrm{g}^{-1}\right.$ dry weight)

${ }^{\text {h}}$ Rodriguez-Amaya et al. (2008)

${ }^{\mathrm{i}} \mathrm{Niizu}$ and Rodriguez-Amaya (2005)

sunlight exposure that may influence the antioxidant capacity of fruits and vegetables. The variability in the compositions and quantities of phytochemicals and antioxidants in different foods indicate the importance of eating a variety of food sources in particular, colored foods, in every meal.

\section{CONCLUSION}

This study focused on the quantification of carotenoids of vegetables commonly consumed in the Middle East countries, including Jordan. In general, the results obtained from this study agree with those reported in the literature and the values fall within the wide ranges of data found in the literature. In any case, raw vegetables can provide high amounts of a variety of carotenoids that are important to human health.

\section{ACKNOWLEDGMENT}

The author thank Dr. G. Tang, Dr. R. Russell, Dr. R. Krinsky, Dr. E. Jonson, Dr. K. Yeum, J. Qin and T. Muzhingi, from Carotenoids and Health Laboratories, Jean Mayer USDA-Human Nutrition Research Center on Aging at Tufts University, Boston, USA for their interest, encouragement and assistant in identification and confirmation of carotenoids.

\section{REFERENCES}

1. Gerster, H., 1997. The potential role of lycopene for human health. J. Am. Coll. Nutr., 16: 109-126. Available

at: http://www.jacn.org/cgi/content/abstract/16/2/109

2. Rao, A. V. and L. G. Rao, 2007. Carotenoids and human health. Pharmacological Research, 55: 207216. Doi: $10.1016 /$ j.phrs.2007.012 
3. Sies, H. and W. Stahl, 1995. Vitamin E and C, $\beta$ carotene and other carotenoids as antioxidants. Am. J. Clin. Nutr., 62: 1315S-1321S. Available at: http://www.ajcn.org/cgi/reprint/62/6/13155.pdf

4. Raju, M., S. Varakumar, R. Lakshminarayana, T. P. Krishnakantha and V. Baskaran, 2007. Carotenoid composition and vitamin A activity of medicinally important green leafy vegetables. Food Chem., 101: 1598-1605. Doi: 10.1016/j.foodchem.2006.04.015

5. Kalt, W., 2005. Effects of production and processing factors on major fruit and vegetable antioxidants. J. Food Sci., 70: 11-19. Doi: 10.1111/j.1365-2621.2005.tb09053.x

6. Marinova, D. and F. Rbarova, 2007. HPLC determination of carotenoids in Bulgarian berries. J. Food Composit. Anal., 20: 370-374. Doi: 10.1016/j.jfca.2006.09.007

7. Azevado, C.H.-de and D.B. Rodriguez-Amaya, 2005. Carotenoid composition of kale as influenced by maturity, season and minimal processing. J. Sci. Food Agric., 85: 591-597. Available at: http://cat.inist.fr/?aModele $=$ afficheN\&cpsidt $=1651$ 7914

8. Ramesh, M.N., 2000. The performance evaluation of a continuous vegetable cooker. Int. J. Food Sci. Technol., 35: 377-384. Doi:10.1046/j.13652621.2000.00392.x

9. Rodriguez-Bernaldo de Quiros, A. and H. S. Costa, 2006. Analysis of carotenoids in vegetable and plasma samples: A review. J. Food Composit. Anal., 19: 97-111. Doi: 10.1016/j.jfca.200504.004

10. Krinsky, N.I., 1993. Actions of carotenoids in biological systems. Annu. Rev. Nutr., 13: 561-587. Doi: 10.1146/annurev.nu.13.070193.003021

11. Mayne, S.T., 1996. Beta-carotene, carotenoids and disease prevention in humans. FASEB J., 10: 690701. Available

at: http://www.fasebj.org/cgi/reprint/10/71690

12. Kim, Y-N., D. W. Giraud and J. A. Driskell, 2007. Tocopherol and carotenoid contents of selected Korean fruits and vegetables. J. Food Composit. Anal., 20 : 458-465. Doi: 10.1016/j.jfca.2007.02.001

13. Krinsky, N.I. and E.J. Johnson, 2005. Carotenoid actions and their relation to health and disease. Molecular Aspects Med., 26: 459-516. Doi:10.1016/j.mam.2005.10.001
14. Palozza, P. and N.I. Krinsky, 1992. Antioxidant effects of carotenoids in vivo and in vitro: An overview. Meth. Enzymol., 213: 403-420. Available at: http://cat.inist.fr $/$ ?aMode $=$ afficheN $\&$ cpside $=4469589$

15. Palace, V.P., N. Khaper, Q. Qin and P.K. Singal, 1999. Antioxidant potentials of vitamin A and carotenoids and their relevance to heart disease. Free Radical Biol. Med., 26: 746-761. Doi: 10.1016/50891-5849(98)00266-4

16. Krinsky, N.I., 2001. Carotenoids as antioxidants. Nutrition, 17: 815-817. Available at: http://jn.nutrition.org/cgi/content/full/132/3/5405

17. Astorg, P., 1997. Food carotenoids and cancer prevention: An overview of current research. Trends Food Sci. Technol., 8: 406-413. ISSN 0924-224. Available at: http://cat.inist.fr/?aModele $=$ afficheN\&cpsidt $=2117$ 398

18. Lako, J., V.C. Trenerry, M. Wahlqvist, N. Wattanapenpaiboon, S. Sotheeswaran and R. Premier. 2007. phytochemical flavonols, carotenoids and the antioxidant properties of a wide selection of Fijian fruit, vegetables and other readily available foods. Food Chem., 101: 17271741. Doi:10.1016/j.foodchem.2006.01.031

19. Stahl, W. and H. Sies, 2005. Bioactivity and protective effects of natural carotenoids. Biochim. Biophys. Acta, 1740: 101-107. Available at: http://www.ncbi.nlm.nih.gov/pubmed/15949675?d opt $=$ Abstract

20. Riso, P. and M. Porrini, 1997. Determination of carotenoids in vegetable foods and plasma. Int. J. Vitamin Nutr. Res., 67: 47-54. Available at: http://verlag.hanshuber.com/Zeitschriften/IJVNR/9 7/vn9701.html\#vn9701_08

21. United States Department of Agriculture, Agricultural Research Service, (2007) National Nutrient Database for Standard Reference, Release 20 Home Page: http://www.nal.usda.gov/fnic/foodcomp/search/.

22. Kandlakunta, B., A. Rajendran and L. Thingnganing, 2008. Carotene content of some common (cereals, pulses, vegetables, spices and condiments) and unconventional sources of plant origin. Food Chem., 106: 85-89. Doi:10.1016/j.foodchem.2007.05.071 
23. Ben-Amotz, A. and R. Fishler, 1998. Analysis of carotenoids with emphasis on 9-cis $\beta$-carotene in vegetables and fruits commonly consumed in Israel. Food Chem., 62: 515-520. Doi: 10.1016/50308-8146(97)00196-9

24. Rodriguez-Amaya, D.B., M. Kimura, H.T. Godoy and J. Amaya-Farfan, 2008. Update Brazilian database on food carotenoids: Factors affecting carotenoid composition. J. Food Composit. Anal., 21: 445-463. Doi:10.1016/j.jfca.2008.04.001

25. Niizu, P.Y. and D.B. Rodriguez-Amaya, 2005. New data on the carotenoid composition of raw salad vegetables. J. Food Composit. Anal., 18: 739-749. Doi:10.1016/j.jfca.2004.09.001

26. Hart, D.J. and K.J. Scott, 1995. Development and evaluation of an HPLC method for the analysis of carotenoids in foods and the measurement of the carotenoid content of vegetables and fruits commonly consumed in UK. Food Chem., 54: 101-111. Doi: 10.1016/0308-8146(95)92669-B
27. Cho, Y-S., K-J. Yeum, C-Y. Chen, G. Beretta, G. Tang, N. I. Krinsky, S. Yoon, Y. C. Lee-Kim, J. B. Blumberg and R. M. Russell, 2007. Phytonutrients affecting hydrophilic and lipophilic antioxidant activitiesin fruits, vegetables and legumes. J. Sci. Food Agric., 87: 1096-1107. Doi: $10.1002 /$ jsfa. 2817

28. Mertz, J.R., E. Shang, R. Piantedosi, S. Wei, D.J. Wolgemuth and W.S. Blaner, 1997. Identification and characterization of a stereospecific human enzyme that catalyzes 9-cis-retinol oxidation. J. Biol. Chem., 272: $\quad 11744-11749 . \quad$ Available at: http://www.jbc.org/cgi/reprint/272/18/11744

29. Prior, R.L. and G. Cao, 2000. Antioxidant phytochemicals in fruits and vegetables: Diet and health implications. Horticultural Sci., 35: 588-592. Available at: http://www.ashs.org/hortsci.html 